\title{
A formação de valores no processo educativo do sujeito concreto
}

Afonso Mancuso de Mesquita

\section{RESUMO}

A formação de valores é um tema inexplorado pela psicologia concreta. No Brasil, seu debate é feito majoritariamente na perspectiva piagetiana. Propomos, neste artigo, iniciar uma análise concreta de seu desenvolvimento. Partimos do pressuposto de que os valores, como unidades da moral, têm natureza cultural e se originam no processo histórico do trabalho. A extensão da valoração para outros campos da vida social cria os valores sociais e a moral. Os valores se desenvolvem como unidade entre processos afetivos e cognitivos, têm base emocional dinâmica e se transformam diretamente pela conceitualização do pensamento. Originam-se como necessidade emocional de bem-estar e chegam a juízos lógicos com fortes implicações subjetivas. Os valores nos mobilizam racional e emocionalmente e medeiam escolhas, uma vez que são parâmetros das alternativas que temos nas ações. A moral se consolida na personalidade a partir da adolescência, quando surgem convicções morais conscientes e a pessoa jovem é capaz de ligar sua própria conduta às relações sociais gerais. A educação valorativa é complexa, pois precisa alterar conceitos e a posição emocional das pessoas frente a relações sociais, isto é, alterar a sociabilidade em um sentido crítico e criar relações coletivizadas para se efetivar.

Palavras-chave: valores sociais; juízo moral;, estados emocionais; psicologia educacional; atividade pedagógica.

\section{ABSTRACT \\ Value formation on concrete subject educational process}

Value formation is an unexplored theme in concrete psychology. In Brazil, it's debate is mostly guided by Piaget's perspective. We propose in this paper to initiate a concrete analysis of it's development. We start from the assumption that values, as moral unities, have cultural nature and originate in historical work process. Values develop as unities between affect and cognition processes, have dynamic emotional basis and are transformed directly by conceptual thought. They originate as emotional needs of well-being and turn into logical judgments with strong subjective implications. Values move us both both intellectually and emotionally and mediate choices, once they are parameter of our action's alternative. Morals consolidate in personality from adolescence on, when moral conscious convictions appear and young people are capable of linking their own conduct with bigger social relations. Value education is complex, as it needs to change people's concepts and emotional position in front of social relations, in other words, to change sociability in a critic sense and create relations of collectiveness to happen.

Keywords: social values; moral judgment; emotional states; educational psychology; pedagogical activity.

O tema da formação de valores é praticamente inexplorado pela psicologia concreta. 0 desenvolvimento moral tem sido dominado no cenário da ciência psicológica brasileira por uma perspectiva piagetiana do problema e as ideias que desenvolveremos aqui são propostas para abertura de um novo caminho analítico, e não teses definitivas sobre esse fenômeno. Julgamos, contudo, que o desenvolvimento moral é tema de grande relevância para a psicologia, devido a sua importância para o próprio desenvolvimento, para a pedagogia e para a organização política da sociedade, como pretendemos demonstrar neste texto. Nesse esforço, buscaremos

\section{Sobre os autores}

A. M. M. https://orcid.org/0000-00020140-0677

Universidade Estadual de Feira de Santana - Feira de Santana, BA ammesquita@uefs.br

\section{Direitos Autorais}

Este é um artigo de acesso aberto e pode ser reproduzido livremente, distribuído, transmitido ou modificado, por qualquer pessoa desde que usado sem fins comerciais. O trabalho é disponibilizado sob a licença Creative Commons CC-BY-NC.

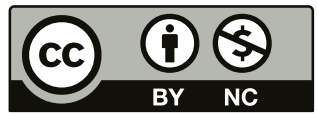




\section{M." INTERACÃO EM PSICOLOGIA}

a definição de conceitos importantes e a fundamentação teórica necessária para acessarmos da forma metodologicamente mais coerente possível uma abordagem concreta do desenvolvimento moral. 0 estudo que serve de base a este texto é nossa tese de doutorado (Mesquita, 2018).

Como dito, a maior parte dos debates teóricos no Brasil hoje sobre o desenvolvimento moral e suas implicações pedagógicas se referem basicamente a Piaget e La Taille (docente e pesquisador, um dos principais piagetianos ativos no país). Mais precisamente, encontramos mais citações a ele que propriamente a Piaget, como em Alencar (2014), Goergen (2005), Müller e Alencar (2012), Oliveira (2001), Pradel e Daú (2009), Scopel e Gomez (2006), entre outros. Todos os fundamentos dessa perspectiva, todavia, estão no livro 0 juízo moral na criança, de Piaget (1994/1932).

Nesse texto, Piaget coloca as teses e conclusões centrais para compreensão de seu problema e entende que a moralidade subjetiva se explica pelos mesmos princípios que o desenvolvimento da inteligência, que resumidamente são três: a psicogênese do desenvolvimento; a mudança de estruturas internas por adaptação ao meio; o apriorismo de tendências funcionais, que servem de motor ao desenvolvimento e movem os processos adaptativos. Em Piaget, tanto a inteligência quanto a moralidade se desenvolvem ao longo da ontogênese, paralelamente uma à outra, mudam de estrutura por adaptação e em função de suas próprias tendências funcionais a priori.

Esse desenvolvimento, então, é mais um autodesenvolvimento, que se inicia e se desdobra na interação de cada indivíduo com as forças e exigências de seu meio. Essa dinâmica interativa provoca efeitos na consciência da criança, pois seus princípios funcionais a priori de adaptação (equilibração, assimilação e acomodação) agem no sentido de colocá-la diante de novas condições para lidar com problemas. É assim que as operações mentais mudam de estrutura e a criança se desenvolve. No seu desenvolvimento moral, ela deve experimentar na própria atividade a relação com o certo, o justo e todos os valores morais.

Uma periodização abreviada do desenvolvimento moral em Piaget seria a seguinte. 0 começo do processo é a ausência total de regras morais, que ele definia como estado da anomia, o estado inicial de desenvolvimento de todas as pessoas. As noções morais nascem como objetos de interação pela ação dos adultos, que as impõem. Assim, a criança tem de lidar com o certo, justo, permitido, bom, etc., e seus antípodas. Piaget, nas suas observações, chega a uma conclusão interessante, que nos parece válida desde que não reflita em extremismo pedagógico, como debateremos no último item do texto), esses valores, importados da imposição adulta, edificam na criança uma moral heterônima, seu segundo estágio.
Sua principal característica é sua fragilidade como princípio moral. A moral heterônima não basta para construir senso de justiça. Isso se deve ao fato de que a ação do adulto não pode ser concebida pela criança como errada, mas tida sempre como verdadeira, pois a criança tem uma forte ligação afetiva com o adulto, que o coloca numa posição de superioridade.

Assim, a autoridade adulta, se bem que constituindo, talvez, um momento necessário na evolução moral da criança, não basta para construir o senso de justiça. Este só se desenvolve na proporção dos progressos da cooperação e do respeito mútuo, de início, cooperação entre crianças, depois cooperação entre crianças e adultos, na medida em que a criança caminha para a adolescência e se considera, pelo menos em seu íntimo, como igual ao adulto (Piaget, 1994, p. 239).

O desenvolvimento moral se completa somente na terceira fase, da moral autônoma, em que as crianças, necessariamente por meio da cooperação, isto é, das atividades entre crianças, experienciam escolhas e dilemas morais isentos da superioridade emocional dos adultos: quando as crianças começam a entender o princípio moral interno a toda regra.

A perspectiva piagetiana, abordada aqui de forma sintética, tem pontos fortes e fracos. Seus pontos fortes, como o estudo teórico parece apontar, são dois: a ideia de que a moralidade se desenvolve na ontogênese e corresponde aos conteúdos experienciados pela criança. E que o desenvolvimento moral depende de relações afetivas, que ele tem um importante componente emocional. Esses dois elementos nos parecem corretos. Os pontos fracos são: 1 - a compreensão de meio e interação, idênticos aos da biologia, o que Vigotski (2001) não considerava válido para a psicologia científica. 2 - A psicogênese da moralidade, que a concebe (bem como todo o desenvolvimento) como criação subjetiva, em que cada pessoa constrói seu próprio senso de justiça (o núcleo do conceito de construtivismo). Se há semelhança social entre distintos pontos de vista individuais, é porque há uma espécie de "sintonização", em que tanto a inteligência como a moralidade devem passar na interação coletiva. 3 - Piaget entende que tanto a inteligência quanto a moralidade têm traços de desenvolvimento anteriores à linguagem. 0 pensamento realmente tem raiz genética diferente da linguagem, segundo Vigotski (2001), mas a moralidade não, pois ela também é produto do salto qualitativo que a linguagem cria no desenvolvimento. 4 - Se concebe o desenvolvimento moral como paralelo ao intelectual, um desdobramento da incompreensão do papel da linguagem e da interfuncionalidade psíquica no desenvolvimento moral. 5 - A compreensão politicamente romântica do bem comum. Piaget (1994) entendia que a moral que dirige as relações sociais entre pessoas adultas era "exatamente a da cooperação" (p. 243), materializado nas sociedades democráticas ocidentais, como se fossem expressão da mais harmônica sintonia de valores sociais. Se a moralidade, como ele 


\section{M." INTERACÃO EM PSICOLOGIA}

dizia, tendia naturalmente ao bem comum, assim como as sociedades tendiam naturalmente às repúblicas democráticas, por serem exemplo de equilíbrio, negociação e justiça, revela-se sua visão ingênua da história, ignorante da luta de classes, e também da moralidade como inerentemente histórica.

Porque, se as sociedades humanas evoluíram da heteronomia para a autonomia e da teocracia gerontocrática sob todas as suas formas para a democracia igualitária [grifo nosso], é bem provável que os fenômenos de condensação social, tão bem descritos por Durkheim, favoreceram primeiramente, a emancipação das gerações uma em geração (sic) às outras e tornaram possível, nas crianças adolescentes, a evolução que acabamos de descrever (Piaget, 1994, p. 243).

Os pontos fracos dessa perspectiva a mostram como insuficientes para uma compreensão concreta do processo. E, pela sua negativa, já podemos identificar traços que para nós são essenciais: 1 - a moralidade é um aspecto da história e muda de acordo com seus processos gerais. Não há, portanto, moralidade fora da história, da luta de classes e dos processos sociais concretos. 2 - Sua origem não é subjetiva e seu estudo psicogenético dificulta a compreensão de seus traços essenciais. 3 - 0 desenvolvimento moral depende do desenvolvimento global das funções psíquicas, cujo mecanismo básico é a mudança de vínculos interfuncionais, convertendo operações imediatas em processos mediados por signos, tese estabelecida desde a contribuição de Vigotski (1995, 2001).

\section{UMA PERSPECTIVA CONCRETA DO DESENVOLVIMENTO DOS VALORES}

\section{GÊNESE HISTÓRICA DOS VALORES}

A moral tem origem histórica e esse é seu traço essencial: é por excelência produto da cultura humana. Não há moral na natureza, não há certo e errado, bom e ruim, justo e injusto; as coisas e seres simplesmente existem, na história da evolução das espécies, as estruturas simplesmente funcionam ou não, sobrevivem ou não. Em suma, na objetividade natural não há sequer traços de intencionalidade ou valoração. A moralidade nasce da necessidade humana de avaliar e se desenvolve como elemento integrante da história, correspondendo a seu conteúdo interno. Por isso, não podemos pensar a moralidade fora da história ou da luta de classes. Não existem, portanto, valores universais e absolutos, como manifestação ideal de um bem ou justiça abstratos. Isso nos posiciona na filosofia no campo da axiologia material, em oposição à axiologia formal (Abbagnano, 1982; Mora, 1977). A axiologia material considera que os valores morais são relativos à história, determinados pela ação de seus próprios sujeitos.
Afonso Mancuso de Mesquita

A origem da moral está ligada a aspectos ontológicos das primeiras formas históricas de valoração, nascidas do próprio processo histórico do trabalho (Lukács, 2012, 2013). Em seu processo, as atividades produtivas do trabalho exigiam avaliação e valoração constante dos objetos, ações e efeitos. Portanto, a origem dos valores era o caráter de utilidade das coisas encontradas ou fabricadas. Os valores eram, assim, necessários para balizar as alternativas possíveis da atividade produtiva, pois o trabalho também abriu à humanidade nascente a possibilidade de escolher o caminho entre diferentes alternativas. Os valores então nasciam do trabalho e o mediavam, serviam reflexivamente de orientação das suas ações, de intencionalidade crescente. Cada ato do trabalho é, segundo Lukács (2013), regulado pelo valor que se almeja alcançar, sua finalidade. Cada movimento do processo de trabalho deve "ser corretamente orientado pelo pôr do fim" (p. 72).

\section{DOS VALORES ECONÔMICOS AOS VALORES SOCIAIS}

A constatação de que os valores nascem como valores econômicos, contudo, ainda não explica o problema psicológico dos valores e da moral. É preciso avançar e o próprio Lukács $(2012,2013)$ nos ajuda nesse sentido. Segundo ele, em sua ontologia marxista, o trabalho é considerado a atividade desencadeadora de processos de autodiferenciação no humano em relação a toda natureza e assim origina todas as demais formas de atividade social. 0 desdobramento do trabalho em outras atividades é o que vai originar o nascimento histórico da moral. E para compreender essa passagem, devemos notar uma característica muito interessante. Enquanto o trabalho se funda com protagonismo da relação sujeito-objeto, outras atividades sociais incorporam seus aspectos de intencionalidade, consciência e valoração para desdobrá-los a relações sujeito-sujeito, ou seja, relações interpessoais. É assim que se originaram do trabalho atividades diferentes dele mesmo, como a arte, a educação, o direito, a filosofia, a moral, etc.

Por isso, os valores econômicos são "também o fundamento ontológico de todas as relações sociais que chamamos 'valores', e por isso também o veículo de todos os tipos de comportamento socialmente relevantes que são chamados de avaliações" (Lukács, 2012, p. 344). Ou seja, historicamente a humanidade aprendeu a avaliar no processo de trabalho, desejando a utilidade das coisas, mas estendemos a avaliação a outros processos da vida. Desse ponto em diante, tudo se torna passível de avaliação: ações, pessoas, ideias, desenhos, histórias, jogos, sons, cores, enfim, praticamente tudo pode ser avaliado e julgado. A moral, portanto, nasce da diferenciação da valoração a outros campos da atividade social.

A rejeição da hierarquia no terreno ontológico liga-se estreitamente à questão de como o valor econômico se 


\section{H. INTERACÃOEM LFP PSICOLOGIA}

relaciona com os demais valores sociais (...). Acreditamos que a necessidade social que põe os valores é, com igual necessidade ontológica, ao mesmo tempo pressuposto e resultado do caráter alternativo dos atos sociais dos homens. No ato da alternativa está contida necessariamente também a escolha entre o que tem valor e o que é contrário ao valor; temos assim, por necessidade ontológica, tanto a possibilidade de escolher o que é contrário ao valor quanto a possibilidade de errar, mesmo tendo escolhido subjetivamente o que é de valor (Lukács, 2012, p. 409).

É essa passagem dos valores econômicos aos sociais que permite a avaliação das ações, escolhas, procederes, consequências, etc., e abre a possibilidade de uma reflexão sobre o certo, o justo, o bom, o desejável e seus contrários, abre a possibilidade de existência da moral, um dos aspectos mais importantes da vida social. Podemos dizer, nesses termos, que os valores são unidades da moral, suas células constitutivas que conservam a mesma qualidade com o todo (serem produtos do julgamento humano), como defendia Vigotski (2001). A moral pode ser compreendida, nesses termos, como sistema de valores.

Mas no que consistem afinal os valores? Observando sua operação, pelo ato de avaliar ou valorar (atribuir valor), concluímos que todo valor é uma qualidade, uma qualidade atribuída e/ou reconhecida nas coisas, ações, pessoas, etc. Tanto para os valores econômicos quanto para os sociais vale o mesmo, a valoração é o ato de atribuir uma qualidade, de qualificar. E tanto no processo do trabalho quanto no campo moral, e isso é central, os valores medeiam escolhas, o que tem grande importância, pois revela o papel que a moral ocupa na estrutura geral da personalidade: a formação do caráter. Sobre seu desenvolvimento, conferir o texto de Célia Regina da Silva e Júlia Mazinini Rosa nesse dossiê.

Em resumo, podemos considerar e concluir que: os valores são unidades vivas da moral; valores sociais e morais são sinônimos; que o problema da moral é ligado ao da vontade, da conduta arbitrária, pois os valores são qualidades que o ser social atribui a coisas e pessoas e que retroagem sobre ele, mediando suas escolhas entre diferentes alternativas. O tema da moral é, portanto, muito próximo ao da liberdade. Essas teses apoiam a ideia que a construção das instâncias morais ocupa papel de destacada importância na estrutura geral da personalidade.

\section{DESENVOLVIMENTO PSICOLÓGICO DOS VALORES}

Os valores sociais se desenvolvem em nós ao longo da ontogênese, como já deve estar evidenciado a essa altura do texto. Aprendemos tanto a valorar as coisas quanto os valores vindos de avaliações prévias, pois já nascemos em meio social onde tudo tem valor. Mas, durante a ontogênese, os valores se desenvolvem, mudam de função em relação à consciência e à personalidade. A questão é: quando podemos dizer que existe uma instância moral constituída na personalidade, quando a criança é capaz de julgar moralmente? Para responder a essa questão, não podemos perder de vista que todo juízo moral, toda avaliação coerente revela processos complexos de pensamento, um juízo é sempre um ato de pensamento. Evidente, então, que o processo não começa por uma moralidade madura, como apontara Piaget. Encontramos confirmação e aprofundamento dessa ideia em Bozhovich (1987).

\section{PERIODIZAÇÃO DO DESENVOLVIMENTO DOS VALORES}

Não temos ainda condição de apresentar uma periodização pormenorizada do seu desenvolvimento na ontogênese, mas é possível demonstrar o movimento geral percorrido pelos valores, que revela por sua vez algumas de suas características psicológicas mais marcantes.

Bozhovich (1987) defende que a valoração pode ser observada desde muito cedo na ontogênese, na primeira infância e na idade pré-escolar.

As investigações psicológicas testemunham que na infância pré-escolar já se formam no pequeno uma determinada autovaloração. Claro, não é igual à das crianças de mais idade, mas tampouco igual à das crianças da primeira infância. Os menores (de 2 a 3 anos) no geral se consideram, independentemente de qualquer coisa, bons. Pelo contrário, nos pré-escolares se forma uma autovaloração que se apoia na avaliação realizada de uma ou outra maneira, do êxito de suas ações, na valoração dos circundantes, na aprovação dos pais. Se pode dizer que na infância pré-escolar se forma realmente uma particular visão infantil de mundo, na que entra certa representação geral sobre o mundo, a atitude frente a ele e a si mesma no dito mundo (Bozhovich, 1987, pp. 270-271) [tradução nossa].

De acordo com suas observações, a autoavaliação já se manifesta no final do segundo ano de vida e sua característica principal é seu caráter quase exclusivamente emocional. $\mathrm{Na}$ avaliação primária falta quase por completo o componente lógico, ela surge sobre o terreno do desejo (não consciente) da criança em receber aprovação por parte das pessoas adultas e conservar seu bem-estar emocional. Então não há propriamente avaliação, mais uma protoavaliação, a expressão direta de uma necessidade emocional. E assim revela-se uma característica importante, a valoração nasce no campo afetivo, corporal. No mundo em que tudo tem valor, a criança também tem e, mesmo sem concebê-lo racionalmente, seu corpo já expressa a necessidade de vinculação emocional positiva com as pessoas adultas. É por isso que a criança nessa idade se avalia sempre como boa e certa, independente do que tenha feito. Ela não considera a realidade externa porque lhe faltam 


\section{MLE INTERACÃO EM PSICOLOGIA}

condições, mas suas emoções já se ligam à valoração mesmo sem juízo racional. Cria-se um terreno para o desenvolvimento.

Na idade pré-escolar, processos de desenvolvimento geral da personalidade da criança já a diferenciam da primeira infância e seu pensamento, sua capacidade de estabelecer relações de identificação permitem incorporar a opinião alheia, o sucesso de suas atividades e a aprovação de pessoas adultas. Como sabemos com a ajuda de Elkonin (1987), essa idade é marcada pelos jogos de papéis sociais, em que a criança demostra reconhecer o mundo social de uma maneira inovadora, se comparada consigo mesma a um, dois anos atrás. A identificação afetiva com papéis sociais, sua reprodução no jogo, a narrativa sobre a realidade, entre outras mudanças, revelam que já tratamos de outra criança. Agora ela é capaz de compreender a realidade de forma mais ampla e evidentemente também muda sua forma de valorar a realidade. Segundo Bozhovich (1985), as crianças nessa fase já são capazes de lidar com valores morais e princípios éticos, mesmo que isso tome contornos particularmente infantis.

Assim, nas condições de comportamento cotidiano e de comunicação com os adultos e também na prática do jogo de papéis, no pré-escolar se forma certo conhecimento generalizado de muitas normas sociais; no entanto, este saber não é totalmente conscientizado pela criança e está unido diretamente a suas vivências emocionais positivas ou negativas. Dito com outras palavras, as primeiras instancias éticas representam por agora só formações sistêmicas relativamente simples, que de qualquer forma constituem os gérmens dos sentimentos morais sobre a base dos quais no futuro se formarão sentimentos e convicções morais completamente maduras (Bozhovich, 1985, p. 268) [tradução nossa]

Mesmo como "formações sistêmicas relativamente simples", elas já existem. Mesmo que a criança em idade pré-escolar não domine conceitos ou abstrações, ela passa a considerar a realidade externa em seus julgamentos e a expressividade dessa nova relação interfuncional entre emoções e pensamento muda e vai se expressando em seus jogos e discurso. 0 êxito das próprias ações é avaliado e sentido com intensidade emocional, como tudo nessa idade; a aceitação, o juízo e opinião das pessoas sobre ela também passam a importar. No estágio anterior era mais simples, se achar boa independente dos fatos, agora ela precisa receber aprovação ou não garante seu bem-estar emocional. Assim, a valoração sai do campo exclusivamente emocional e se transforma como processo interfuncional.

Em torno de sete anos de idade, a criança passa por um período crítico de seu desenvolvimento, em que seu pensamento a permite compreender a duplicidade da experiência entre externa e interna (Vygotski, 1996a). Isso permite, segundo ele, a diferenciação do campo interno da vivência.
"Aos sete anos se forma na criança uma estrutura de vivências que a permite compreender o que significa 'estou alegre', 'estou desgostoso', 'sou boa', 'sou má', ou seja, nela surgem a orientação consciente de suas próprias vivências" (p.380) [tradução nossa]. Ou seja, nasce a possibilidade de ela ter vivências de vivências, o que traz sua própria experiência no mundo para outra condição de consciência. Por isso, podemos afirmar que nessa idade surgem as primeiras instâncias propriamente morais na consciência da criança, pois passa a refletir conscientemente sobre seus estados internos, suas próprias ações, conclusões, etc.

Entre sete e doze anos, a criança geralmente vive uma idade estável guiada pelo estudo escolar (Elkonin, 1987), em que sua conduta se direciona para a aquisição de meios sociais de conduta, especialmente aos conhecimentos veiculados pela escola. É uma fase de desenvolvimento intelectual decisiva para a formação das estruturas desenvolvidas do pensamento, período em que a criança vai paulatinamente dominando os conceitos e chega às formas mais desenvolvidas de pensamento (Vigotski, 2001; Davídov, 1988). Isso tem implicações decisivas para o processo de valoração, pois a criança vivencia de outra forma a realidade social, tanto sua posição nela como sua compreensão dela são totalmente diferentes dos anos pré-escolares. E é esse avanço dos processos de pensamento que vai levar os valores a seu nível de desenvolvimento mais elevado, bem como a mudança de sua função mediante o todo da personalidade. Há dois indícios para essa afirmação, uma vinda de Elkonin (1987) e outra de Vygotski (1996b) e Bozhovich (1985).

Para Elkonin (1987), a passagem à adolescência ou crise dos doze anos corresponde à idade menos estudada em psicologia. "No entanto, precisamente a passagem ao período adolescente é considerado em psicologia como o mais crítico" (p. 119) [tradução nossa]. Ela é caracterizada pela destituição das antigas referências afetivas dos jovens, as pessoas adultas, e jovens da mesma idade passam a ocupar esse lugar. Isso os leva a uma nova atividade, a comunicação íntima-pessoal. 0 que guia o desenvolvimento nesse período são as relações de companheirismo, respeito mútuo, amizade e comunidade espiritual entre os jovens. Nasce nesse exercício um código moral especial, um código de companheirismo, ao qual eles se subordinam voluntariamente e reproduzem de forma crítica em seus círculos de relação as principais formas de atividade social. 0 nascimento desse código tem grande importância para a edificação da personalidade do adolescente. "O 'código de companheirismo' reproduz por seu conteúdo as normas mais gerais das inter-relações existentes entre os adultos na sociedade dada" (Elkonin, 1987, p. 120) [tradução nossa]. Essa crise do desenvolvimento marca um novo movimento de mudança no desenvolvimento moral das crianças/jovens. 


\section{H. INTERACÃO EM LF PSICOLOGIA}

Releva-se a importância desse período para o desenvolvimento pleno dos valores morais e os sentidos mais gerais da vida humana. É na adolescência que o processo de formação de valores na ontogênese dá seus passos mais importantes. Segundo Vygotski (1996b), "os anos da adolescência são, antes de tudo, anos de formação da concepção de mundo político-social, anos em que vão se formando, no fundamental, suas concepções da vida, da sociedade, das pessoas, quanto nascem umas ou outras simpatias ou antipatias sociais" (p. 67) [tradução nossa]. A possibilidade intelectual de compreender e julgar a realidade permite que se organizem em um único sistema os valores morais dos jovens. Nasce nessa idade, por exemplo, o interesse pela política, um sintoma de grande importância, por ela ser sumamente valorativa. São as novas formas de pensamento conceitual que permitem que esse tipo de interesse surja, compreensão e valoração são faces da mesma moeda. Mais que isso, "a formação de conceitos abre ante o adolescente o mundo da consciência social e impulsiona inevitavelmente ao intenso desenvolvimento da psicologia e da ideologia de classe, a sua formação" (Vygotski 1996b, p. 66) [tradução nossa]. Não é somente o interesse pela política, mas a própria formação de uma visão ideológica da realidade.

Bozhovich (1985) faz avançar a compreensão de Vigotski sobre esse período. Ela diz que a neoformação típica da idade escolar avançada, a adolescência, é a visão moral de mundo, que leva a personalidade a seu último grau de desenvolvimento. Ela parte da tese de Vigotski, de que o salto qualitativo típico dessa idade era o domínio do conceito pelo pensamento.

L. S. Vigotski, de acordo com sua concepção psicológica geral, via a causa do salto qualitativo na consciência moral do jovem no desenvolvimento do pensamento conceitual, bastante aperfeiçoado já nessa etapa. 0 curso de seus argumentos consistia no seguinte: a formação do pensamento conceitual torna acessível ao adolescente jovem a assimilação do novo conteúdo, em particular a assimilação da consciência social, da ideologia e da cultura de classe (Bozhovich, 1985, pp. 327-328) [tradução nossa].

Ela, contudo, não entendia que a visão moral de mundo era um desdobramento automático da formação do pensamento conceitual, mas uma síntese complexa, mais ligada à situação social de desenvolvimento do que às mudanças internas ou condições externas. Bozhovich (1985) identifica uma importante necessidade dos adolescentes, que impulsiona seu desenvolvimento moral, a de encontrar para si um lugar na sociedade, que chama de necessidade de autodeterminação [social]. Essa necessidade é afetivamente importante, sua satisfação ou não determina o bem-estar emocional. Podemos até especular como a atividade de comunicação íntima-pessoal e a coletividade que ela enseja determinam a formação da necessidade de autodeterminação social, é provável que exista essa relação, mas Bozhovich (1985) não a explora. Enfim, é sobre a base dessa necessidade que os adolescentes assimilam as exigências morais do coletivo, o que é valorado e como, bem como sua própria autovaloração e exigências que assume para si. É nessa conjunção que se formam os ideais sociais minimamente estáveis, que sustentarão as convicções morais que regularão seus atos e escolhas. Formam-se, assim, pela primeira vez, conviç̧ões morais conscientes. 0 adolescente se faz mais livre em suas escolhas, ganha autonomia frente a determinações externas, se compreende como "senhor das suas circunstâncias" (Bozhovich, 1985, p. 331), entende-se como ativo em uma sociedade que há pouco mal concebia. Ele começa a agir em função de suas próprias convicções morais, que têm para ele caráter "extraordinariamente afetivo" (Bozhovich, 1985, p. 331). E, finalmente, ela conclui que nessa idade, sobre a base de uma concepção moral superior, "tem lugar o verdadeiro estabelecimento da personalidade destes alunos" (Bozhovich, 1985, p. 331) [traduções nossas]. Ou seja, a formação da visão moral de mundo e o nascimento nas convicções morais conscientes é, na sua visão, o ato final do desenvolvimento da personalidade na ontogênese, seu último salto qualitativo.

\section{VALORES, MORAL E INTERFUNCIONALIDADE PSÍOUICAS}

O desenvolvimento dos valores na ontogênese deve ser compreendido como fazia Bozhovich $(1985,1987)$, como uma síntese complexa, que só pode ser explicada pela interfuncionalidade dos processos psíquicos. Eles têm como base necessidades emocionais diretas, pelo primado temporal das emoções, que compõe a vida psíquica antes da linguagem e pensamento. Mas o segredo de seu desenvolvimento é a intelectualização pela linguagem, eles nascem e se transformam estruturalmente devido à nomeação. Nem poderia ser diferente, a intelectualização das funções é algo intrínseco ao próprio desenvolvimento, como está estabelecido na perspectiva vigotskiana da psicologia, pois o ato da fala é também um ato de pensamento, como Vigotski (2001) (e em praticamente todos os textos dos anos 30 ) revela no significado da palavra. É próprio do efeito da linguagem a formação de novos sistemas psicológicos por meio do estabelecimento de redes interfuncionais e intercorticais. Os valores são, sob esse enfoque, posições emocionais que vão ganhando contornos lógicos e vão se transformando em juízos propriamente ditos.

Por outro lado, as próprias emoções também se desenvolvem ao longo da ontogênese e formam generalizações afetivas que não existiam antes. A fala intelectualiza as emoções e elas deixam de cumprir meramente funções naturais, evolutivas, para dar origem a sentimentos, aspirações, desejos, necessidades, motivos e afetos sociais. É assim que nasce o desejo de conhecer o mundo, as identificações afetivas com outras pessoas, a necessidade de imitar no jogo de papéis 


\section{H*' INTERACÃO EM PSICOLOGIA}

ociais, de aprender o que pessoas adultas sabem, de compreender o mundo junto a seu coletivo e de encontrar para si uma posição valorizada na sociedade. É para a complexidade real do desenvolvimento que Bozhovich (1985) chama atenção. Os novos tipos de generalização afetiva são parte importante da vida psíquica, se não seu fim último, e as próprias emoções que servem de base aos valores se desenvolvem e ganham conteúdo social. Zaporozhets (2003) fizera um estudo que investigou a relação entre a educação emocional das crianças e seu desenvolvimento moral, comprovando a relação entre moral e afeto no processo educativo.

Uma perspectiva concreta do desenvolvimento dos valores, dialética, portanto, não os explicam pelo desenvolvimento do pensamento nem pelo das emoções, mas pelos sistemas interfuncionais formados pela atividade histórica da humanidade e pela contradição entre intelecto e afeto que assim se movimenta. A compreensão lógica, o julgamento racional, são processos subsumidos na valoração, da mesma forma que a atitude emocional. É essa unidade que explica como os valores medeiam escolhas, pois se ligam aos principais motivos da vida; não há como ser indiferente ao valor social das coisas. Valorar é pensar e também se implicar emocionalmente com o valorado, é se posicionar frente aos fatos. 0 posicionamento social é um produto avançado do desenvolvimento, síntese de todos os processos anteriores, ponto em que o caráter se torna uma instância estável e organizativa da personalidade. A moral se torna parte importante de quem somos.

\section{A MORAL COMO SISTEMA E SUA IMPORTÂNCIA PARA A PSICOLOGIA}

Há outra característica da moralidade que mencionamos, mas não exploramos, é seu caráter sistêmico. Ela forma sistemas em que há uma dinâmica de hierarquização entre os valores. Nem todos eles são iguais entre si e cumprem a mesma função. Tanto em termos socialmente objetivos quanto psicológicos, a moral é um sistema com centro, periferia e hierarquia entre os valores. É necessário então descobrir ou definir quais os centros valorativos de um sistema objetivo ou subjetivo de forma que ele mantenha sua integridade, sua coerência.

Uma abordagem consequente da moral deve, portanto, investigar quais são seus centros valorativos e compreendê-la pelo todo de seu sistema. Vygotski (1996b) já dera a pista fundamental de que os sistemas morais estão ligados ao aspecto ideológico da sociedade. E pensando na gênese histórica da moral, temos motivos para suspeitar que a própria origem da ideologia, do direito e da moral estão ligadas. Mas, o que é seguro de afirmar é que a compreensão geral sobre a vida e sobre a sociedade nos leva à totalidade dos sistemas morais. Por exemplo, a ideologia liberal toma o direito e a liberdade individuais como centros de seu sistema valorativo, o direito à propriedade privada é valorado como um direito universal e inalienável de todas as pessoas. Daí quando o direito burguês ameniza uma pena de assassinato mediante invasão de propriedade, revela-se uma hierarquia de valores, em que a vida humana é relativizada mediante ação contra a propriedade. Outro exemplo, vivo e candente, é o que vivemos nesse momento da história do Brasil e do mundo, em que a principal relutância em tomar todas as medidas preventivas contra a disseminação do novo coronavírus é o impacto na economia, ou seja, na geração e acumulação de capital. Dependendo do sistema de valores que internalizamos e elaboramos ao longo da vida, nos posicionamos de forma diferente em relação a esse mesmo problema. Em oposição, se tomamos a ideologia socialista como um outro sistema valorativo, em que o direito irrestrito à vida ocupa seu centro, fica fácil compreender e concordar com uma frase do famoso revolucionário latino-americano, Che Guevara: "Vale milhões de vezes mais a vida de um único ser humano do que toda a propriedade do homem mais rico do mundo". É simples, a vida vale mais que a propriedade material, não importa a proporção. Isso se revela quando olhamos a moral como sistema valorativo.

A abordagem da moral social nos leva a um segundo nível de interfuncionalidade. Se do ponto de vista psicológico a valoração se desenvolve articulada a todo o sistema da consciência, a capacidade de posicionamento frente à realidade coloca a subjetividade em unidade com os fatos sociais e isso também é produto do desenvolvimento psicológico, que as pessoas alcancem a possibilidade de engajamento social voluntário, que exista alguma unidade consciente entre as questões subjetivas e os problemas sociais. Isso nos leva ao problema da personalidade como sistema de centro único, ou que a vida subjetiva persiga valores maiores, grandes objetivos que lhe confiram sentido e direção. Vygotski (1997) tomara essa ideia de Espinosa para sua própria reflexão.

Para Espinosa, a ideia única é a de Deus ou da natureza. Psicologicamente isso não é necessário em absoluto. Mas o homem pode certamente reduzir a um sistema não só funções isoladas, mas criar também um centro único para todo o sistema. Espinosa mostrou este sistema no plano filosófico; há pessoas cuja vida é um modelo de subordinação a um fim, que mostraram na prática que isso é possível. À psicologia se coloca a tarefa de mostrar como verdade científica esse tipo de aparição de um sistema único (Vygotski, 1997, p. 87) [tradução nossa].

Interessante notar que ele diz que reduzir todo o sistema a um centro único não é necessário, mas é possível, que à psicologia cabe provar a existência do que se mostra na prática, que há pessoas que subordinam sua vida a um fim. Não temos condição de teorizar sobre isso com precisão, mas vale lembrar a contribuição dada por A. N. Leontiev com sua teoria 


\section{M." INTERACÃO EM PSICOLOGIA}

da atividade, em que revela a importância de motivos geradores de sentido, não só para a atividade, mas para a vida psíquica como um todo, que o elevam a alcançar a felicidade e o sentido da vida.

Se conforma uma personalidade diferente, com um destino diferente quanto o motivo-fim diretor se eleva até o genuinamente humano e não isola o homem, mas que funde sua vida com a vida das pessoas, com seu bem. De acordo com as circunstâncias que se mostram seu destino, esses motivos vitais podem adquirir conteúdo muito diverso e diferente significação objetiva, mas só eles são capazes de criar a justificativa psicológica interior da existência [grifo nosso] do homem que constitui o sentido e a felicidade da vida [grifo nosso] (Leontiev, 1978, p. 172) [tradução].

Seria uma extrapolação grosseira dizer que o sentido da vida se desdobra de um centro moral da personalidade, não se trata disso. Todavia, ao mesmo tempo, a direção oposta parece ter algum significado, isto é, a identificação e a entrega pessoal a um propósito, a um bem comum, maior, parece sem exageros favorecer a construção de um sentido existencial, de orientar a busca pela felicidade, que no fim das contas não é individual.

Além disso, a própria preocupação em encontrar o centro de cada sistema valorativo tem caráter eminentemente políti$\mathrm{co}$, pois traria à superfície os valores sociais das pessoas, fato importante no embate ideológico da sociedade.

De todo modo, esse debate, mesmo que inconcluso, já demonstra a relevância envolvida na investigação do desenvolvimento social e psicológico dos valores e a diferença que uma abordagem correta do problema faz na revelação de seus traços definidores.

\section{O PROCESSO DE EDUCAÇÃO VALORATIVA DO SUJEITO CONCRETO}

As implicações pedagógicas de uma educação valorativa são muitas. Sobre esse assunto, sugerimos para aprofundamento a leitura de um livro recém-publicado, de Jorge Neves (2020), que ajudará a compreender melhor a tarefa que se nos coloca. Um diagnóstico feito nele é de que a história da pedagogia mostra uma oscilação entre centralismo de valores e centralismo de conhecimentos, em que ambos aparecem dissociados, isto é, ou o ensino se estrutura na vivência valorativa ou na transmissão de conhecimentos.

Foi a reforma da Escola Nova, no início do século passado que propôs o centralismo dos valores. Segundo Neves (2020), "A síntese dessa formação moral baseada em determinados valores aparece, principalmente, em torno da valoração positiva da autonomia e da democracia na prática educativa", que se daria "apesar do adulto educador" (p. 128) [grifos no original]. Ou seja, os valores democráticos da Escola Nova se dedicam a combater o "adultocentrismo", declarando a igualdade de condições entre todos na escola para a produção e compartilhamento de cultura e conhecimento, mostrando o lado negativo da ideia de Piaget sobre o desenvolvimento moral, como se o adulto, só por ser adulto, o atrapalhasse. 0 extremismo pedagógico, ao qual nos referimos antes, é tomar o adulto como estorvo ao desenvolvimento. A cooperação entre crianças não exclui o papel educador da pessoa adulta, portadora de conteúdo social.

Mas, do lado das pedagogias críticas, acabamos por cair no extremo oposto e os valores acabam "por não ser objeto de preocupação sistemática no pensamento pedagógico brasileiro crítico, configurando assim o centralismo do conhecimento" (Neves, 2020, p. 154). Com todo o reconhecimento do papel histórico da socialização de conhecimentos escolares, o pensamento pedagógico crítico não oferece hoje no Brasil um modelo válido para a educação valorativa, ao contrário, quase a ignora. Mas não é possível fazer realmente uma pedagogia crítica sem a dimensão dos valores, pois como direcionar tudo que se aprende contra um sistema de pensamentos e posturas, de valores, afinal?

A ausência da dimensão valorativa da produção e da socialização do conhecimento, fundamental para a compreensão das questões políticas e ideológicas de nosso tempo, reduz a questão aos termos pouco e muito conhecimento, conhecimento sistematizado e espontâneo, sob a hipótese de que dominar o que o dominador domina produz libertação, e nunca subordinação aos valores dominantes. Reduz-se o problema da aprendizagem ao caminho do senso comum à consciência filosófica, sem levantar o problema de a consciência filosófica poder ser conservadora valorativamente (Neves, 2020, p. 158).

É evidente então que a educação valorativa do sujeito concreto, tomado em suas múltiplas determinações históricas, é interesse de uma pedagogia crítica. A situação que nos encontramos, entretanto, é de necessidade de superação de ambos centralismos, dos valores e dos conhecimentos, em direção a uma síntese crítica que permita a educação valorativa do sujeito concreto. É preciso então dar "um salto na abstrata defesa do conhecimento sistematizado para um patamar de articulação entre o conhecimento sistematizado e os elementos da moral própria da perspectiva do trabalho em seus valores mais autênticos, como a insubordinação e a solidariedade de classe" (Neves, 2020, p. 189-190).

Lamentavelmente, não há ainda um estudo aprofundado desse tipo de educação, mas podemos antever algumas de suas características constitutivas por meio das peculiaridades do desenvolvimento moral. Uma vez que os valores têm base emocional dinâmica, que segue e muda com o desenvolvimento das próprias emoções, é preciso que pensemos 


\section{H. INTERACÃO EM 4T PSICOLOGIA}

o contexto social real no qual relações interpessoais acontecem, ou seja, do tipo de sociabilidade vigente em nossa sociedade. Se vivemos em uma sociedade radicalmente desigual, que nos impele a relações competitivas e individualistas, que trata de forma violenta e injusta pessoas negras, mulheres, LGBTIs, periféricas e pobres, as vivências gerais que orientam as posições emocionais das pessoas em relação às demais e à vida são marcadas por essas mesmas características. Se o mundo capitalista nos joga umas contra as outras, as formas de coligação e grupalização serão sempre marcadas por essas características. Por isso a educação valorativa não pode ser puramente teórica, não podemos conduzi-la de fora ao comportamento e à reflexão, ela deve alterar a lógica geral das relações intersubjetivas, de alguma forma, o eixo da sociabilidade vivenciada no processo educativo. Tendo em vista que os valores estão em disputa na sociedade, a educação valorativa não pode deixar de pensar as formas de sociabilidade vivenciadas na escola ou outros espaços de educação formal. Isso coloca um desafio às pedagogias críticas, pois a tarefa ultrapassa a socialização de conhecimentos, que deve ser incorporada, mas não sem politizar a sociabilidade da escola.

Defendemos que o único tipo de alternativa que temos para iniciar esse processo é propor a coletivização da sociabilidade escolar, pois assim criaríamos (ou ao menos tensionaríamos) outro tipo de relação de alteridade e vínculos afetivos entre as pessoas. Isso exige repensar muitos aspectos da organização da escola e para isso, infelizmente, temos poucos modelos. Em Mesquita (2018) encontramos um debate um pouco mais detido sobre algumas experiências, como a experiência educativa da Comuna de Paris, alguns aspectos da pedagogia soviética, a alteração brusca das formas de sociabilidade gerada pelas ocupações de escola no Brasil no ano de 2015 e a experiência com a formação de grêmios estudantis em Bauru-SP, que expressam movimento geral de coletivização e estabelecimento de relações mais igualitárias, nos saltos de qualidade que os movimentos políticos costumam propiciar, como, por exemplo, a igualdade de gênero que foi instantaneamente defendida e exercitada na Comuna e nas ocupações.

Outro exemplo é que o M. Pistrak (2011) dizia sobre os coletivos infantis, que eles não nascem pelo agrupamento de crianças no mesmo lugar. Ou seja, as escolas não formam coletivos automaticamente. 0 coletivo se define pela consciência de interesses em comum e se a escola quiser criar um, deve trazer às crianças novos interesses. "A escola só permitirá um amplo desenvolvimento e uma coesão íntima do coletivo das crianças no momento em que for o lugar (e o centro) da vida infantil, e não apenas o lugar de sua formação" (M. Pistrak, 2011, p. 144). A recentralização da vida, contudo, é algo complexo e exige novos objetivos sociais para se estruturar, o que envolve transformações profundas nos conhecimentos, hábitos, objetivos, valorações, rotinas e vínculos emocionais.
Por isso o coletivismo parece a via mais interessante, porque reúne todas essas características.

A formação dos coletivos coloca muitos desafios, pois ruma na contramão das formas dominantes de sociabilidade, e isso é sempre difícil. Um de seus produtos contra-hegemônicos é valorar na prática como desejáveis a igualdade de direitos e deveres, horizontalizar relações, criar a noção de propriedade coletiva e ampliar a relevância do 'nós' em relação ao 'eu'. Essas mudanças práticas na sociabilidade e nos objetivos sociais, em sua orientação política, desdobram-se nas relações interpessoais, que por sua vez têm impactos subjetivos, no sentido de criar outro solo para a formação de valores. Quando as pessoas precisam estar juntas para alcançar objetivos coletivos, as importâncias mudam de lugar, elas passam a depender umas das outras, fato que cria novas mediações para as relações, desenvolvem consciência dos interesses comuns, como diria Pistrak (2011). Se queremos ensinar não somente os conteúdos escolares, mas também a insubordinação e a solidariedade de classe, a via que nos parece mais profícua é a coletivização mais radical possível da sociabilidade escolar. Essa parece ser a melhor via para a educação moral na escola da classe trabalhadora.

Se a escola pública da sociedade burguesa permite isso e em que medida, é algo para debatermos e pelo qual temos que lutar. A experiência da formação de grêmios estudantis tem se provado um caminho possível desde dentro do cotidiano escolar. As ocupações também, mas na medida em que rompem o cotidiano, o que as tornam uma experiência distinta. Caldart (2013) nos oferece ainda outro modelo, que é a educação formal de dentro do movimento social de luta pela terra, que nos mostra mais possibilidades de florescimento de uma educação valorativa que a própria escola pública, pois a vinculação entre objetivos do movimento e conteúdos aprendidos é orgânica. "Nosso pressuposto básico é da necessária relação entre projeto educativo e projeto histórico. Assumimos o projeto histórico da classe trabalhadora: porque é a nossa classe e porque é a classe portadora de futuro: sociedade, humanidade" (Caldart, 2013, p. 02). Enquanto na escola pública muitas vezes essa relação é meramente externa, ou pior, não existem objetivos coletivos, a função da escola é na melhor das hipóteses a capacitação individual para o mercado de trabalho. A organicidade entre o processo educativo e objetivos coletivos é condição decisiva para a educação valorativa.

Em suma, a tarefa de uma educação valorativa não é simples e para a efetivarmos necessitamos de objetivos políticos em comum, nova sociabilidade, novos vínculos afetivos e novos pensamentos, que sustentariam a formação de coletivos. Se isso pode ser criado na escola pública, é o caminho. Mas outros espaços também podem favorecer formação intencional de valores emancipatórios para a classe trabalhadora, como os movimentos políticos. Cabe nos guiarmos na história. 


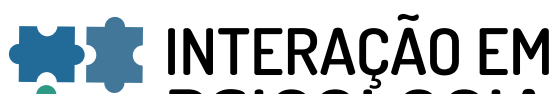 ET PSICOLOGIA}

\section{CONTRIBUIÇÃO DE CADA AUTOR}

Certifico que o autor participou suficientemente do trabaIho para tornar pública sua responsabilidade pelo conteúdo. A contribuição de cada autor pode ser atribuída como se segue:

AMM é responsável por todo o estudo e pela respectiva redação.

\section{DECLARAÇÃO DE CONFLITOS DE INTERESSE}

0 autor declara que não há conflitos de interesse no manuscrito submetido.

\section{REFERENNCIAS}

Alencar, H. M., Marchi, B. F., Couto, L. L. M., Romaneli, M. S., \& Lima, M. G. (2014). Educação em valores morais: juízos de profissionais no contexto escolar. Revista Quadrimestral da Associação Brasileira de Psicologia Escolar e Edu cacional, 2(18), 255-264. https://doi.org/10.1590/2175$3539 / 2014 / 0182742$

Bozhovich, L. I. (1985). La personalidad y su formación en la edad infantil. Editorial Pueblo y educación.

Bozhovich, L. I. (1987). Las etapas de formación de la personalidad en la ontogénesis. In: Davídov, V. V. , Shuare, M. (Orgs.). La Psicología Evolutiva y Pedagógica en la URSS: Antología. Editorial Progreso.

Caldart, R. S. (2013). Desafios do vínculo entre trabalho e educação na luta e construção da Reforma Agrária Popular. $36^{a}$ Reunião Anual da Anped, GT Trabalho e Educação.

Davídov, V. V. (1988). La enseñanza escolar y el desarrollo psíquico. Editorial Progreso.

Goergen, P. (2005). Educação de valores no mundo contemporâneo. Educação e Sociedade, 92(26), 983-1011. https:// doi.org/10.1590/S0101-73302005000300013

Leontiev, A. N. (1978). Actividad, Consciencia y Personalidad. Ediciones Ciências del Hombre.

Lukács, G. (2012). Para uma ontologia do ser social (Vol. 1). Boitempo.

Lukács, G. (2013). Para uma ontologia do ser social (Vol. 2). Boitempo.

Mesquita, A. M. A. (2018). A formação psicológica de valores morais no contexto da sociabilidade competitiva e individualista na educação: apontamentos para a atividade pedagógica. [Tese de Doutorado, Unesp]. http://hdl.handle. net/11449/153907
Müller, A. \& Alencar, H. M. (2012). Educação moral: o aprender e o ensinar sobre justiça na escola. Educação e Pesquisa, 2(38), 453-468. https://doi.org/10.1590/S151797022012000200012

Neves, J. T. (2020). Valores sociais, educação e resistência: fundamentos ontológico e contradições históricas. Lutas Anticapital.

Oliveira, R. J. (2001) Ética na escola: (re)acendendo uma polêmica. Educação \& Sociedade, 76, 112-231. https://doi. org/10.1590/S0101-73302001000300012

Piaget, J. (1994). O juízo moral na criança. Summus Editorial.

Pistrak, M. M. (2011). Fundamentos da escola do trabalho. Expressão popular.

Pradel, C. \& Daú, J. A. T. (2009). A Educação para valores e as políticas públicas educacionais. Ensaio: avaliação e políticas públicas em educação, 64(17), 521-548. https://doi. org/10.1590/S0104-40362009000300007

Scopel, D. T. \& Gomez, M. S. (2006). O papel da escola na superação do preconceito. Revista Educação e tecnologia, 1. http://webcache.googleusercontent.com/search?q=cache:WCzYiTfYFXcJ:www.faacz.com.br/revistaeletronica/links/edicoes/2006_01/ edutec_delza_preconceito_2006_1.pdf+\&cd=1\&hl=p$\mathrm{t}-\mathrm{BR} \& \mathrm{ct}=\mathrm{clnk} \& \mathrm{gl}=\mathrm{br} \& \mathrm{client}=\mathrm{ubuntu}$

Vygotski, L. S.(1995). Historia del desarrollo de las funciones psíquicas superiores. In: Vygotski, L. S. Obras Escogidas III. Visor y Editorial Progreso.

Vygotski, L. S.(1996a). La crisis de los siete años. In: Vygotski, L. S. Obras Escogidas IV. Visor y Editorial Progreso.

Vygotski, L. S. (1996b). Paidología del adolescente. In: Vygotski, L. S. Obras Escogidas IV. Visor y Editorial Progreso.

Vygotski, L. S. (1997). Sobre los sistemas psicológicos. In: Vygotski, L. S. Obras Escogidas I. Visor y Editorial Progreso.

Vigotski, L. S. (2001). A construção do pensamento e da linguagem. Martins Fontes.

Vigotski, L. S. (2010). Quarta aula: a questão do meio na pedologia. Psicologia USP, 21(4), 681-701. https://doi. org/10.1590/S0103-65642010000400003

Zaporozhets, A. V. (2002). Toward the Question of the Genesis, Function, and Structure of Emotional Processes in the Child. Journal of Russian and East European Psychology, 2(40), 45-66. https://doi.org/10.2753/RP010610405400345

Recebido em: 13/04/2020

1a decisão editorial em: 20/07/2020 Aprovado em: 03/08/2020 